\title{
Suicide completion in secondary mental healthcare: a comparison study between schizophrenia spectrum disorders and all other diagnoses
}

Javier-David Lopez-Morinigo ${ }^{1 *}$, Andrea C Fernandes ${ }^{2}$, Chin-Kuo Chang ${ }^{2}$, Richard D Hayes ${ }^{2}$, Matthew Broadbent ${ }^{2}$, Robert Stewart ${ }^{2}$, Anthony S David ${ }^{1}$ and Rina Dutta ${ }^{2}$

\begin{abstract}
Background: Suicide completion is a tragic outcome in secondary mental healthcare. However, the extent to which demographic and clinical characteristics, suicide method and service use-related factors vary across psychiatric diagnoses remains poorly understood, particularly regarding differences between 'schizophrenia spectrum disorders (SSD)' and 'all other diagnoses', which may have implications for suicide prevention in high risk groups.
\end{abstract}

Methods: 308 patients who died by suicide over 2007-2011 were identified from the South London and Maudsley NHS Foundation Trust Biomedical Research Centre Case Register. Demographic, clinical, services use-related factors, 'full risk assessment' ratings and the Health of the Nation Outcome Scale (HONOS) scores were compared across psychiatric diagnoses. Specifically, differences between patients with and without SSD were investigated.

Results: Patients with SSD ended their lives at a younger age, were more frequently of Black ethnicity and had higher levels of social deprivation than other diagnoses. Also, these patients were more likely to have HONOS and 'risk assessment' completed. However, patients who had no SSD scored significantly higher on 'self-injury' and 'depression' HONOS items and they were more likely to have the following 'risk assessment' items: 'suicidal ideation', 'hopelessness', 'feeling no control of life', 'impulsivity' and 'significant loss'. Of note, 'disengagement' was more common in patients with SSD, although they had been seen by the staff closer to the time of suicide than in all-other diagnoses. Whilst 'hanging' was the most common suicide method amongst patients with non-SSD, most service users with a SSD diagnosis used 'jumping' (from heights or in front of a vehicle).

Conclusions: Suicide completion characteristics varied between SSD and other diagnoses in patients receiving secondary mental healthcare. In particular, although clinicians tend to more frequently recognize suicide risk as a focus of concern in patients who have SSD, who are therefore more likely to have a detailed risk assessment documented; 'known' suicide risk factors appear to be more relevant in patients with non-SSD. Hence, the classic suicide prevention model might be of little use for SSD.

Keywords: Suicide completion, Secondary mental healthcare, Schizophrenia spectrum disorders

\footnotetext{
* Correspondence: javier.lopez-morinigo@kcl.ac.uk

${ }^{1}$ Department of Psychosis Studies, King's College London, Institute of

Psychiatry, De Crespigny Park, PO Box 68, London SE5 8AF, UK

Full list of author information is available at the end of the article
} 


\section{Background}

Suicide is a serious international public health problem. Every year almost one million people die by suicide around the world [1]. Of note, suicide has become especially concerning among young people as one of the three leading causes of death in the most economically productive age group (15-44 years) and the second leading cause of death in 15-19 year olds [2]. Since 2008, suicide prevention has become a major priority within World Health Organization mental health policies [3]. However, suicide prevention strategies have yielded mixed results so far (see [4]).

Recent literature on suicide seems to support a 'suicidal spectrum' ranging from suicidal ideation to suicide completion, with decreasing prevalence and increasing lethality [5]. With regard to suicide completion, psychological autopsy studies have revealed that about $90 \%$ of people who killed themselves had a 'psychiatric disorder', contributing to $47-74 \%$ of the population risk of suicide, and with half of suicide completers meeting criteria for depression [6,7]. In other words, the presence of a psychiatric condition appears to be the strongest risk known factor for suicide [6]. It could therefore be envisaged that better management of mental disorders might reduce suicide rates. More specifically, secondary mental health services may play a crucial role in 'suicide prevention' [1].

While a list of risk factors have been strongly associated with 'suicidal behaviour', it remains unclear the extent to which such 'known' risk factors vary across psychiatric diagnoses [8]. In particular, a better understanding of associations between risk factors and diagnoses may lead to the development and implementation of diagnosis-driven suicide prevention strategies in secondary mental health services. For instance, limiting access to instruments of suicide has been demonstrated to reduce suicide rates at a population level (e.g. $[9,10])$. However, it remains unclear whether there are specific associations of psychiatric diagnoses with suicide completion methods [11].

Suicide has been found to be the largest single cause of excess mortality in schizophrenia [12,13]. However, the rate of suicide in schizophrenia has been recently demonstrated to be lower, from $2 \%$ [14] to 5\% [15], than the 'classic' figure of $10 \%[16,17]$. Of note, while some recognised general suicide risk factors have been replicated in schizophrenia patients such as being male, living alone and hopelessness; specific suicide risk factors have also been linked to schizophrenia such as lower treatment adherence [18]. Patients with schizophrenia tend not to report suicidal ideation [19], which is a common suicide risk factor for most other psychiatric conditions [4]. Also, suicide risk assessment in schizophrenia remains underutilized [20]. It therefore seems that the classic suicide prevention model has been less helpful in schizophrenia spectrum disorders than in other diagnoses. Specific suicide completion characteristics in patients with schizophrenia and related disorders in comparison to other diagnoses have not been investigated as fully.

In the UK, over the last two decades the Department of Health has aimed to reduce suicides at a national level [21]. In keeping with this, instruments such as the Health of the Nation Outcome Scale (HoNOS) [22] and structured clinical risk assessments have been strongly recommended [23] and widely used by mental health teams. The extent to which the 'known' risk factors for suicide evaluated by such instruments vary across psychiatric diagnoses in patients who took their lives, is also unknown.

We aimed to investigate differences across diagnoses in a sample of patients receiving secondary mental healthcare from teams supervised by Consultant Psychiatrists (i.e. not those treated solely by general practitioners (family physicians) in primary care) who went on to die from suicide. Specifically, sociodemographic and clinical variables, including HoNOS and 'risk assessment' ratings and 'service use'-related factors, and suicide methods were compared between patients with and without schizophrenia spectrum disorders (SSD) who all died by suicide. Hence, our methodology was not designed to test potential suicide risk factor differences across diagnoses since all the participants had the same fatal outcome. Instead our research question was to investigate differences between patients with and without SSD in a sample of secondary mental health service users who all ended their lives.

\section{Methods}

\section{Sample}

The sample comes from the South London and Maudsley (SLaM) Biomedical Research Centre (BRC) Case Register. SLaM is an NHS Trust which provides secondary mental health care to four boroughs in South-East London (UK): Lambeth, Southwark, Lewisham and Croydon. Approximately 1.23 million inhabitants reside in this geographic catchment area, which as a whole was found to be comparable with other populations of London in terms of age, gender, education and socio-economic status distributions [24]. Fully-electronic health records have been in use across all SLaM services since 2006, and in 2007-08 the Clinical Record Interactive Search (CRIS) system was built which renders de-identified copies of these available for research use with appropriate governance structures [24]. Under UK law, anonymised data can be analysed without prior consent, and CRIS has received ethical approval in this respect as a data resource for secondary analyses from the Oxfordshire Research Ethics Committee C (reference: 08/H0606/71 + 5), currently accessing data on over 250,000 patients. The same Research Ethics approval also covers the pseudonymised linkage between CRIS data and those from the Office for National Statistics (ONS) in March 
2012 [25] which registers all deaths in the UK and the official cause of death, including suicide and the method of suicide according to ICD-10 classification [26].

The study sample for our analysis was composed of those patients who were 'active' to SLaM (i.e. had at least one face-to-face contact with a clinical member of staff) at any point before 31st December 2011, and who had died by suicide (according to the ONS [25] certificate of death) during the period 1st January 2007 to 31st December 2011, including those with an 'undetermined cause of death' (ICD-10 Y codes) [26]. Of note, in the UK most 'open verdicts' are very likely to be deaths by suicide as the coroner, who under UK law determines the cause of death, is required to provide evidence of suicide intent 'beyond reasonable doubt' [27].

\section{Measures}

\section{Demographic and clinical variables}

Date of birth, gender, ethnicity, 'hearing, visual or mobility impairments' (recorded as present/absent) and ICD-10 diagnosis are compulsory fields in the source clinical records system and were analysed. Social deprivation was estimated with the 'Index of Multiple Deprivation' (IMD). In particular, area-level deprivation scores were available through an anonymous link created in CRIS between lower super output area residence code of the latest permanent address (a geographic unit comprising approximately 400 households) and summary data for that area from 2001 UK Census output. The Index of Multiple Deprivation is derived from seven domains: income, employment, health, education, housing and services, crime and environment [28].

\section{Diagnoses}

Distributions and labelling of ICD-10 [26] primary diagnoses in the sample are summarized in Table 1 . In particular, ICD-10 diagnoses [26] were made by the treating consultant psychiatrist, including the use of the OPCRIT system [29] for those patients with psychotic disorders, which has been demonstrated to have high reliability across the Trust psychiatrists [30], who are mandatorily trained in the use of this tool. As a result, those patients who were just seen on one occasion such as a single presentation to A\&E or one outpatient appointment were more likely not to be diagnosed as reported below. For analyses described here, categories were hierarchically created from ICD-10 codes [26]. Thus, only one of the following exclusive diagnostic categories were recorded if the patient had received more than one ICD-10 primary diagnosis: 'F2' - 'schizophrenia spectrum disorder' (SSD); 'F31 and F32.3' - 'Affective Psychosis'; 'F32.1, F32.2, F33, F34 and F4' - 'Mood disorder/Neuroses'; 'F0 and F1' - 'Organic/Drugs'; 'F5, F6 and the remaining categories' were grouped as 'All other diagnoses'. 94
Table 1 Diagnoses

\begin{tabular}{|c|c|c|}
\hline ICD-10 diagnosis & No. completed suicide & Diagnostic categories \\
\hline \multirow[t]{2}{*}{ F2 ever } & 54 & $\begin{array}{l}\text { Schizophrenia } \\
\text { spectrum disorder }\end{array}$ \\
\hline & & $54(17.5 \%)$ \\
\hline Non-F2 & 197 & \\
\hline F00-09 & 10 & Organic/Drugs \\
\hline F10-19 & 35 & $45(14.6 \%)$ \\
\hline F31 & 17 & Affective Psychoses \\
\hline F32.3 & 6 & $23(7.5 \%)$ \\
\hline F32, F33, F34 & 38 & $\begin{array}{l}\text { Mood Disorders } \\
\text { and Neuroses }\end{array}$ \\
\hline$F 40-48$ & 21 & 59 (19.2\%) \\
\hline F50-59 & 1 & Others \\
\hline F60-69 & 10 & $33(10.7 \%)$ \\
\hline Others & 22 & \\
\hline F99 & 16 & Diagnosis 'unknown' \\
\hline Z71.1 & 21 & $94(30.5 \%)$ \\
\hline $\begin{array}{l}\text { ICD-10 diagnosis } \\
\text { unrecorded }\end{array}$ & 57 & \\
\hline Total & 308 & 308 \\
\hline
\end{tabular}

ICD-10: International Classification of Mental and Behavioural Disorders [24].

remaining patients (30.5\%) were labelled as 'Diagnosis Unknown' because they either had a F99 or Z71.1 ICD-10 diagnosis or no diagnosis was recorded. Patients with two or more ICD-10 [26] primary diagnoses over time were included in only one of the above categories according to such hierarchy. For instance, a patient with two primary ICD-10 diagnoses such as F2 and F0 was classified as SSD. Whilst many patients with SSD have other comorbidities such as cannabis misuse [31], given the higher stability of schizophrenia diagnosis over time [32], we chose this category as the first in our hierarchical system. This allowed us to create two clinically meaningful categories to compare: those patients with SSD and those with non-SSD.

\section{Suicide ascertainment and suicide method}

Suicide method was ascertained from that recorded in the ONS Certificate of Death [25] (ICD-10 codes) [26] and the following groups were considered: hanging X83.8, drowning - X71, cutting - X78, poisoning - X64 and Y1, jumping (either from high place or in front of a vehicle) - X80, X81, burning - X76, X77 and undetermined cause of death - Yxx.

\section{Health of the Nation Outcome Scale (HoNOS)}

The Health of the Nation Outcome Scale (HoNOS) has been a widely used outcome measure in British mental health services since its introduction in the 1990s, found to be a reliable and valid instrument to assess clinical outcomes, and to have easy applicability to clinical settings 
[22]. HoNOS is formed of 12 items which assess psychiatric symptoms (e.g. depressed mood or hallucinations), alcohol/drugs use and social needs such as relationship problems or daily living activities. Each item is scored on a Likert scale from 0 (absent) to 4 (maximum severity), and the 12 scores are summed to create total scores, i.e. the higher the score, the more complex/severe the case. The last HoNOS recorded for each patient was used for the purposes of this study.

\section{Risk assessment}

'Full risk assessment' is a compulsory target across the Trust when 'high risk' is determined from a 'brief risk assessment', which is mandatory for all active cases. All patients who have been seen on at least one occasion by a member of the staff have a 'brief risk assessment' documented, which is a narrative record of the patient's risk: i) to one's self; ii) to others and iii) from others. If the patient is deemed at 'high' risk in any of these domains, a 'full risk assessment' needs to be completed, which consists of a structured assessment taking the form of present/absent tick-boxes enquiring about widely recognised risk factors for three major clusters: suicide, violence and self-neglect. For this study, only suicide risk assessment was taken into account, which is composed of 15 items (shown in Table 2) including suicidal history, hopelessness, alcohol misuse, living alone or disengagement. Positive responses can be summed to create total scores, i.e. the higher the score the greater the suicide risk [33]. The most recent full risk assessment was considered for these analyses.

\section{Statistical analyses}

Distributions of continuous variables were inspected by histograms and parametric and non-parametric tests were used in order to examine differences across the above 'diagnostic categories' with regard to demographic and clinical variables. Post-hoc analyses investigated intergroups differences. People dying from suicide with/without SSD were compared in the following respects: i) on demographic and clinical variables using student $\mathrm{t}$ tests, Mann-Whitney U tests and Chi-square tests, as appropriate; ii) on suicide methods, calculating odds ratios and adjusting for age at the time of death and ethnicity; iii) on HoNOS, where completed, both individual HoNOS item (Mann-Whitney-U) and total scores (student t-test); iv) on full risk assessment scores for the 40 (13\%) patients with this information (t-test). All analyses were conducted using SPSS version 20.0 (SPSS Inc, Chicago, Il, USA).

\section{Results}

Of 120,216 SLaM 'active' service users until the $31^{\text {st }}$ December 2011, 308 who died by suicide over 2007-2011 were identified from the SLaM BRC CRIS.

Table 2 Risk Assessment: Completion rates, individual items and total scores comparison in SSD and non-SSD suicide completers

\begin{tabular}{|c|c|c|c|c|c|}
\hline $\begin{array}{l}\text { Completion rate } \\
40(13.0 \%)\end{array}$ & $\begin{array}{l}\text { Total sample } \\
\mathrm{N}=40\end{array}$ & $\begin{array}{l}\text { SSD N }=19 \\
(19 / 54=35.2 \%)\end{array}$ & $\begin{array}{l}\text { non-SSD N = 21 } \\
(21 / 254=8.3 \%)\end{array}$ & $\begin{array}{l}\text { ORs }(95 \% \text { Cls) } \\
6.02(2.94-12.31)\end{array}$ & $\begin{array}{l}\text { Fisher's exact } \\
\text { test } P<0.001\end{array}$ \\
\hline Individual items & & & & & $p$-value \\
\hline Suicidal History & $26(65)$ & $11(57.9)$ & $15(71.4)$ & $0.55(0.15-2.05)$ & ns \\
\hline Lethal Method & $15(37.5)$ & $5(26.3)$ & $10(47.6)$ & $0.39(0.10-1.49)$ & ns \\
\hline Plan to end life & $8(20)$ & $2(10.5)$ & $6(28.6)$ & $0.29(0.05-1.68)$ & ns \\
\hline Suicidal ideation & $16(40)$ & $4(21)$ & $12(57.1)$ & $0.2(0.05-0.81)$ & 0.027 \\
\hline Hopelessness & $18(45)$ & $4(21)$ & $14(66.6)$ & $0.13(0.03-0.55)$ & 0.005 \\
\hline Distress & $17(42.5)$ & $7(36.8)$ & $10(47.6)$ & $0.64(0.18-2.27)$ & ns \\
\hline No control of life & $15(37.5)$ & $4(21)$ & $11(52.4)$ & $0.24(0.06-0.98)$ & 0.038 \\
\hline Alcohol Misuse & $11(27.5)$ & $7(36.8)$ & $4(19.0)$ & $2.47(0.59-10.40)$ & ns \\
\hline Impulsivity & $18(45)$ & $5(26.3)$ & $13(61.9)$ & $0.22(0.06-0.84)$ & 0.031 \\
\hline Living alone & $18(45)$ & $8(42.1)$ & $10(47.6)$ & $0.80(0.23-2.80)$ & ns \\
\hline Poor physical health & $9(22.5)$ & $4(21)$ & $5(23.8)$ & $0.85(0.19-3.79)$ & ns \\
\hline Significant loss & $18(45)$ & $5(26.3)$ & $13(61.9)$ & $0.22(0.06-0.84)$ & 0.031 \\
\hline Disengagement & $9(22.5)$ & $7(36.8)$ & $2(9.5)$ & $5.54(0.98-31.25)$ & 0.060 \\
\hline Recent Discharge from hospital & $11(27.5)$ & $5(26.3)$ & $6(28.6)$ & $0.89(0.22-3.59)$ & ns \\
\hline Family History & 0 & $0(0)$ & $0(0)$ & $\mathrm{n} / \mathrm{a}$ & ns \\
\hline Total score & & $4.11 \pm 2.88$ & $6.24 \pm 2.19$ & & 0.012 \\
\hline
\end{tabular}

SSD: schizophrenia spectrum disorder; OR: odds ratio; Cl: confidence interval; ns: non-significant; in bold: statistically significant differences. 
Sociodemographic and clinical characteristics of the sample As shown in Table 1, 54 patients (17.5\%) had a diagnosis within the schizophrenia spectrum (F2-ICD10). 'Mood disorders', including 'affective psychosis' (23 patients, $7.5 \%)$ and 'non-psychotic mood disorders and neuroses' (59, 19.2\%), was the most common diagnosis. Also, 45 suicide completers (14.6\%) were diagnosed with 'organic disorders or drugs dependence' and 33 marginal cases (10.7\%) had 'other' (known) diagnosis such as ObsessiveCompulsive Disorder (OCD), Attention Deficit Hyperactivity Disorder (ADHD) and Autism Spectrum Disorders (ASD). Of note, 94 patients (30.5\%) had no recorded diagnosis, which in most cases $(69,73.4 \%)$ was related to having had just one face-to-face contact with the staff (e.g. a single presentation to A\&E).

Sociodemographic and clinical characteristics are compared across multiple diagnoses in Table 3, and specifically between those with and without SSD in Table 4. No diagnostic differences were observed in gender; however, age at the time of suicide was younger in those with SSD than the remainder. There were significant group differences in ethnicity across suicide completers' diagnoses with Black ethnicity more frequent in patients presenting with SSD. Although there were no significant differences in IMD scores across diagnoses (Table 3), these were higher in SSD compared to the remainder. Hearing, visual or mobility impairment did not vary significantly across all diagnoses but mobility impairment was more common in SSD than the remainder. SSD cases had received longer duration of care from the Trust teams and had been seen by a member of the staff substantially more recently before the suicide event.

\section{Suicide method}

As shown in Tables 5 and 6, 'hanging' was the most common suicide method in the sample overall (131, 42.5\%). SSD suicide cases had more frequently utilized 'jumping, while 'hanging' was significantly more frequent among the remainder. There were no suicides by firearms.

\section{Health of the Nation Outcome Scale (HoNOS)}

116 suicide completers (37.6\%) had at least one HoNOS completed. Completion rates differed across diagnoses: $83.3 \%$ of those with SSD; $35.0 \%$ of the remainder $(\mathrm{OR}=$ 12.9, 95\% CI 6.0-27.7, $\mathrm{p}<0.001)$. On individual items, patients with SSD scored significantly higher on 'hallucinations \& delusions', while subjects with non-SSD had higher scores on 'depressed mood' and 'self-injury' (Table 7).

\section{Full risk assessment}

As described in Table 2, only 40 suicide completers (13\%) had at least one full risk assessment completed:

Table 3 Demographics, clinical and service use-related factors for suicide completers across diagnoses

\begin{tabular}{|c|c|c|c|c|c|c|c|c|}
\hline & $\begin{array}{l}\text { Total } \\
\text { sample } \\
308\end{array}$ & $\begin{array}{l}\text { Schizophrenia } \\
\text { spectrum disorder } \\
54(17.5)\end{array}$ & $\begin{array}{l}\text { Affective } \\
\text { psychosis } \\
23(7.4)\end{array}$ & $\begin{array}{l}\text { Mood disorders/ } \\
\text { neuroses } \\
62(20.1) \\
\end{array}$ & $\begin{array}{l}\text { Organic/ } \\
\text { drugs } \\
45(14.6)\end{array}$ & $\begin{array}{l}\text { Other } \\
\text { diagnoses } \\
30(9.7)\end{array}$ & $\begin{array}{l}\text { Diagnosis } \\
\text { unknown } \\
94(30.5) \\
\end{array}$ & p-value \\
\hline Age at the time of death & $42.7 \pm 14.0$ & $39.3 \pm 11.9$ & $49.3 \pm 14.2$ & $47.0 \pm 16.5$ & $44.7 \pm 14.0$ & $39.3 \pm 13.4$ & $40.4 \pm 12.5$ & 0.040 \\
\hline Gender (males) & $211(68.5)$ & $38(70.3)$ & $10(43.5)$ & $40(64.5)$ & $36(80.0)$ & $19(63.3)$ & $68(72.3)$ & 0.052 \\
\hline \multicolumn{9}{|l|}{ Ethnicity } \\
\hline White British & $157(51)$ & $22(40.7)$ & $18(78.3)$ & $45(72.6)$ & $30(75.0)$ & $13(4.3)$ & $29(30.8)$ & $<0.001$ \\
\hline Other white background & $30(9.7)$ & $4(7.4)$ & $1(4.3)$ & $3(4.8)$ & $8(16.6)$ & $2(6.6)$ & $12(12.7)$ & ns \\
\hline South Asian & $5(1.6)$ & $2(3.7)$ & $0(4.3)$ & $2(3.2)$ & $0(0)$ & $0(0)$ & $1(1.0)$ & ns \\
\hline $\begin{array}{l}\text { African and } \\
\text { other black }\end{array}$ & $25(8.1)$ & $12(22.2)$ & $0(0)$ & $1(1.6)$ & $1(2.2)$ & $1(3.3)$ & $10(10.6)$ & $<0.001$ \\
\hline Caribbean & $11(3.6)$ & $8(14.8)$ & $1(4.3)$ & $0(0)$ & $2(4.4)$ & $0(0)$ & $0(0)$ & $<0.001$ \\
\hline Mixed and others & $16(5.2)$ & $3(5.5)$ & $1(4.3)$ & $2(3.2)$ & $2(4.4)$ & $4(13.3)$ & $4(4.2)$ & ns \\
\hline Missing & $64(20.7)$ & $3(5.5)$ & $2(8.7)$ & $9(14.5)$ & $2(4.4)$ & $10(33.3)$ & $38(40.4)$ & $<0.001$ \\
\hline Deprivation & $28.0 \pm 13.7$ & $32.1 \pm 11.4$ & $22.5 \pm 13.8$ & $27.2 \pm 13.5$ & $30.2 \pm 13.1$ & $26.1 \pm 13.3$ & $27.1 \pm 14.3$ & ns \\
\hline Hearing Impairment & $4(1.3)$ & $1(1.85)$ & $0(0)$ & $1(1.6)$ & $1(2.2)$ & $0(0)$ & $1(1.0)$ & ns \\
\hline Visual Impairment & $2(0.6)$ & $0(0)$ & $0(0)$ & $0(0)$ & $2(4.4)$ & $0(0)$ & $0(0)$ & ns \\
\hline Mobility Impairment & $8(2.6)$ & $4(7.4)$ & $0(0)$ & $1(1.6)$ & $0(0)$ & $1(3.3)$ & $2(2.1)$ & ns \\
\hline First language English & $147(47.7)$ & $34(62.9)$ & $10(43.5)$ & $30(48.4)$ & $28(62.2)$ & $11(36.6)$ & $34(36.2)$ & 0.008 \\
\hline $\begin{array}{l}\text { Length of service } \\
\text { contact (median, days) }\end{array}$ & 184 & 1294 & 292 & 184 & 513 & 48 & 0 & $<0.001$ \\
\hline $\begin{array}{l}\text { Last face-to-face to } \\
\text { death (median, days) }\end{array}$ & 70 & 10 & 19 & 93 & 31 & 177.5 & 560 & $<0.001$ \\
\hline
\end{tabular}

In bold: statistically significant differences. 
Table 4 Demographics, clinical and service use-related factors: SSD vs. non-SSD suicide completers

\begin{tabular}{|c|c|c|c|c|c|}
\hline & $\begin{array}{l}\text { Total sample } \\
308\end{array}$ & $\begin{array}{l}\text { SSD } \\
54(17.5) \\
\end{array}$ & $\begin{array}{l}\text { non-SSD } \\
254(82.5) \\
\end{array}$ & $\begin{array}{l}\text { OR } \\
(95 \% \mathrm{Cl}) \\
\end{array}$ & p-value \\
\hline Age at death & $42.7 \pm 14.0$ & $39.3 \pm 11.9$ & $43.5 \pm 14.4$ & & 0.048 \\
\hline Gender (males) & $211(68.5)$ & $38(70.3)$ & $173(68.1)$ & $1.11(0.58-2.11)$ & 0.87 \\
\hline \multicolumn{6}{|l|}{ Ethnicity } \\
\hline White & $187(60.7)$ & $26(48.4)$ & $161(63.4)$ & $0.54(0.30-0.97)$ & 0.046 \\
\hline Black & $36(11.7)$ & $20(37.0)$ & $16(6.3)$ & $8.75(4.14-18.5)$ & $<0.001$ \\
\hline Others & $85(27.6)$ & $8(14.8)$ & $77(30.3)$ & $0.40(0.18-0.88)$ & 0.020 \\
\hline Deprivation & $28.0 \pm 13.7$ & $32.1 \pm 11.4$ & $27.1 \pm 14.0$ & & 0.010 \\
\hline Mobility Impairment & $8(2.6)$ & $4(7.4)$ & $4(0.01)$ & $5.00(1.21-5.66)$ & 0.034 \\
\hline First language English & $147(47.7)$ & $34(62.9)$ & $113(44.5)$ & $2.12(1.15-3.88)$ & 0.016 \\
\hline Length of service contact (median, days) & 184 & 1294 & 81 & & $<0.001$ \\
\hline Last face-to-face to death (median, days) & 70 & 10 & 146 & & $<0.001$ \\
\hline
\end{tabular}

SSD: schizophrenia spectrum disorder; OR: odds ratio; Cl: confidence interval. In bold: statistically significant differences.

19 SSD (35.2\%) vs. 21 non-SSD (8.3\%) (OR = 6.0, 95\% CI $2.9-12.3, \mathrm{p}<0.001)$. Mean $\pm \mathrm{SD}$ total scores were lower in SSD $(4.1 \pm 2.9)$ compared to non-SSD $(6.2 \pm 2.2 ; \mathrm{t}=-2.65$, $\mathrm{p}=0.012$ ). With regard to individual items, patients who had SSD receiving a full risk assessment were less likely to be recorded as having 'suicidal ideation,',hopelessness,' 'lack of control over life,' 'impulsivity' or a 'significant loss'; while 'disengagement' was more common in individuals with SSD at borderline statistical significance.

\section{Discussion}

\section{Principal findings}

In a large clinical case register sourced from electronic mental health records linked to a national death certification database, we investigated characteristics of patients dying from suicide, comparing these between those with and without SSD. Four major conclusions can be drawn from our results.

First, a population of secondary mental healthcare users who ended their lives over the study period (2007-2011) was identified from our case register. Nearly one in five of the suicide completers had been diagnosed with schizophrenia spectrum disorders (SSD), which is approximately double that in previous reports [8], although this may reflect the high prevalence of psychotic disorders in South-East London [34] and our methodology does not permit us to calculate a suicide rate in each diagnostic category.

Second, several differences were found in sociodemographic characteristics between SSD and other diagnoses. Specifically, those subjects with SSD died at a younger age, they tended to be more commonly of Black origin and they were more socially deprived than non-SSD suicide completers, which replicated previous findings in our catchment area with non-suicide samples [35,36]. Given the study methodology, particularly the lack of a control non-suicide group, no causality conclusions can be inferred from the above findings. Thus, while some previous studies have shown an association between psychosis and Black ethnicity [34], other groups have raised concerns regarding a diagnostic bias towards psychosis in Black people [37]. However, previous studies from our group, which carefully considered the above potential bias in the methodology, revealed a link between

Table 5 Suicide method across diagnoses

\begin{tabular}{|c|c|c|c|c|c|c|c|c|}
\hline & $\begin{array}{l}\text { Total sample } \\
308\end{array}$ & $\begin{array}{l}\text { Schizophrenia } \\
\text { spectrum disorder } \\
54(17.5)\end{array}$ & $\begin{array}{l}\text { Affective } \\
\text { psychosis } \\
23(7.4)\end{array}$ & $\begin{array}{l}\text { Mood } \\
\text { disorders } \\
62(20.1)\end{array}$ & $\begin{array}{l}\text { Organic/ } \\
\text { drugs } \\
45(14.6)\end{array}$ & $\begin{array}{l}\text { Other } \\
\text { diagnoses } \\
30 \text { (9.7) }\end{array}$ & $\begin{array}{l}\text { Diagnosis } \\
\text { unknown } \\
94(30.5)\end{array}$ & $p$-value \\
\hline Hanging & $131(42.5)$ & $14(25.9)$ & $13(56.5)$ & $34(54.8)$ & $17(37.7)$ & $11(36.6)$ & $42(44.6)$ & 0.025 \\
\hline Drowning & $21(6.8)$ & $5(9.2)$ & $2(8.7)$ & $5(8.0)$ & $1(2.2)$ & $2(6.6)$ & $6(6.4)$ & ns \\
\hline Sharp object & $9(2.9 \%)$ & $2(3.7)$ & $0(0)$ & $1(1.6)$ & $1(2.2)$ & $1(3.3)$ & $4(4.2)$ & ns \\
\hline Poisoning & $66(21.4)$ & 7 (12.9) & $5(21.7)$ & $9(14.5)$ & 17 (37.7) & $10(33.3)$ & $18(19.1)$ & 0.015 \\
\hline Jumping & $56(18.2)$ & 17 (31.5) & $3(13.0)$ & $13(20.9)$ & $3(6.6)$ & $5(16.6)$ & $15(16.0)$ & 0.042 \\
\hline Burning & $3(0.9)$ & $2(3.7)$ & $0(0)$ & $0(0)$ & $0(0)$ & $0(0)$ & $1(1.0)$ & ns \\
\hline Undetermined & $22(7.4)$ & 7 (12.9) & $0(0)$ & $0(0)$ & $6(13.3)$ & $1(3.3)$ & $8(8.5)$ & 0.025 \\
\hline
\end{tabular}

SSD: schizophrenia spectrum disorder; OR: odds ratio, Cl: confidence interval. In bold: statistically significant differences. 
Table 6 Suicide method: schizophrenia spectrum disorder (SSD) vs. non-SSD

\begin{tabular}{|c|c|c|c|c|c|}
\hline & $\begin{array}{l}\text { Total sample } \\
308\end{array}$ & $\begin{array}{l}\text { SSD } \\
54(17.5)\end{array}$ & $\begin{array}{l}\text { non-SSD } \\
254(82.5)\end{array}$ & $\begin{array}{l}\text { ORs } \\
\text { (95\% Cls) }\end{array}$ & Fisher's exact test $p$-value \\
\hline Hanging & $131(25.9)$ & $14(25.9)$ & $117(46.0)$ & $0.4(0.2-0.7)$ & 0.005 \\
\hline Poisoning & $66(21.4)$ & $7(12.9)$ & $59(23.2)$ & $0.5(0.2-1.1)$ & ns \\
\hline Jumping & $56(18.2)$ & 17 (31.5) & 39 (15.3) & $2.5(1.3-4.9)$ & 0.008 \\
\hline Cutting & $9(2.9)$ & $2(3.7)$ & $7(2.7)$ & $1.4(0.3-6.7)$ & ns \\
\hline Burning & $3(0.9)$ & $2(3.7)$ & $1(0.4)$ & $9.7(0.9-109.4)$ & 0.081 \\
\hline Drowning & $21(6.8)$ & $5(9.2)$ & $16(6.3)$ & $1.5(0.5-4.4)$ & ns \\
\hline Undetermined & $22(7.4)$ & $7(12.9)$ & $15(5.9)$ & $2.4(0.9-6.1)$ & 0.091 \\
\hline
\end{tabular}

SSD: schizophrenia spectrum disorder; OR: odds ratio; Cl: confidence interval; ns: non-significant. In bold: statistically significant differences.

Black Ethnicity, social deprivation and psychosis in our catchment area [31]. Hence, our findings concerning differences between patients with and without schizophrenia spectrum disorders who died by suicide in terms of social deprivation and ethnicity might reflect specific sociodemographic characteristics of our population irrespective of such a fatal outcome despite previous literature showing a relationship between ethnicity and suicide [38]. Nevertheless, further research is warranted in this area.

Third, with regard to suicide method, we found that while hanging was the most common suicide method in the whole sample, patients with SSD were more likely to have used 'jumping' (from an height or in front of a vehicle) to take their lives, consistent with previous literature on 'suicide completion and method' $[4,11,39,40]$. This may have implications for suicide prevention. Limiting availability of lethal methods has been demonstrated to reduce suicide rates at a population level [4]. Also, restricting access to suicide hotspots such as heights through safety barriers (e.g. [10]) and railway lines by installing platform edge doors [41] has been reported to reduce overall suicide rates at such places [42]. In keeping with the above, no suicides by gunshot were identified in our sample, which is likely to be due to the restrictions to firearms access in the UK. Hence, by linking our findings concerning suicide method and diagnosis to previous literature there are grounds to speculate that installation of physical barriers in bridges, tall buildings and railway stations near psychiatric hospitals may prevent patients with SSD from suicide. Nonetheless, further research should be conducted in this area.

Fourth, it seems that clinicians deem patients who have SSD at greater risk of suicide and they are therefore more likely to have received a full risk assessment, as well as having a higher likelihood of HoNOS completion, which

Table 7 Health of the Nation Outcome Scale (HoNOS): Completion rates, individual items and total scores comparison in SSD and non-SSD suicide completers

\begin{tabular}{|c|c|c|c|}
\hline $\begin{array}{l}\text { Completion rate } \\
116(37.6 \%)\end{array}$ & $\begin{array}{l}\text { SSD } 45 \\
(45 / 54=83.3 \%)\end{array}$ & $\begin{array}{l}\text { non-SSD } \\
69(69 / 254=35.0 \%)\end{array}$ & $\begin{array}{l}p<0.001 \\
O R=12.89(6.00-27.73)\end{array}$ \\
\hline Individual items & & & p-value \\
\hline Agitated behaviour & 0.44 & 0.51 & ns \\
\hline Self-injury & 0.18 & 1.03 & $<0.001$ \\
\hline Drinking \& Drugs & 0.71 & 0.70 & ns \\
\hline Cognitive Problems & 0.31 & 0.59 & ns \\
\hline Physical Illness & 0.82 & 0.68 & ns \\
\hline Hallucinations/Delusions & 1.22 & 0.29 & $<0.001$ \\
\hline Depressed Mood & 0.89 & 1.80 & $<0.001$ \\
\hline Other mental problems & 1.38 & 1.65 & ns \\
\hline Relationship problems & 1.07 & 1.17 & ns \\
\hline Daily living & 0.87 & 0.87 & ns \\
\hline Living & 0.67 & 0.59 & ns \\
\hline Occupational problems & 0.96 & 0.78 & ns \\
\hline Total score & 9.55 & 10.52 & ns \\
\hline
\end{tabular}

SSD: schizophrenia spectrum disorder; OR: odds ratio; Cl: confidence interval; ns: non-significant. In bold: statistically significant differences. 
is relatively in contrast to previous literature [20]. However, the above instruments may have been completed due to concerns raised regarding other risks such as violence and/or self-neglect.

Interestingly, known suicide risk factors tended to be less commonly recorded as present in those who have SSD than in subjects with non-SSD. Of relevance, disengagement was found to be (significantly) more frequent in SSD than nonSSD suicide completers, however. Despite the above, half of suicide completers with a SSD had been seen by a member of the staff shortly before such a fatal outcome, which is in line with previous studies showing the relative inability of clinicians to predict imminent suicide risk in individuals with SSD under their care [43].

With regard to HoNOS items in our sample of suicide completers, while symptoms severity such as depressed mood and 'hallucinations \& delusions' differed across diagnostic groups, as expected, interestingly 'social needs', 'cognitive deficits' or 'alcohol/drugs problems' did not (significantly) vary between patients with SSD and without SSD. In this regard, it could be speculated that the care package provided to these patients by the Trust succeeded in meeting their complex social needs and accordingly the most recent HoNOS scores regarding social needs did not reveal differences across the above diagnostic categories. An alternative explanation, which could not be tested in this study due to using a sample of suicide completers without control group, might be that there are no associations between (met/unmet) social needs, psychiatric diagnosis and suicidality. In addition, we replicated the role of 'depression' and history of self-injury in suicide completion, both irrespective of diagnosis and across the different diagnoses [44], including SSD [18,45].

Regarding classic risk factors, we replicated the role of suicidal history and suicidal ideation, hopelessness, impulsivity and significant loses in suicide risk irrespective of diagnosis $[44,46]$ being highly prevalent, although they were more frequent in the non-SSD group.

Hence, it seems that overall suicide might be less predictable, and therefore less preventable, in patients with SSD than in those without $[18,47,48]$. However, disengagement was specifically more common in the SSD group than in all-other diagnoses. Hence, there are grounds to consider that insight, which has been associated with adherence [49], might be a protective factor for suicide in schizophrenia spectrum disorders [18] despite common assertions to the contrary (see [50] for review). In addition, stigma, which prevents patients from receiving proper care [51], may play a relevant role in suicide risk in patients under secondary mental health services who disengage, particularly among those with SSD [52]. Nevertheless, more research is needed to test whether anti-stigma campaigns can reduce suicide rates both at a population level and in secondary mental health services users.

\section{Strengths and limitations}

This study focused on the rare outcome of suicide completion and therefore adds to previous findings from samples of suicide attempters (e.g. [53]). Moreover, by using a large case register linked to national mortality data, all those patients receiving secondary mental healthcare in our catchment area who died by suicide over 2007-2011 were included in the study with the only exception of those who ended their lives outside the UK. Since only a small proportion of patients living in South-East London receive private mental health care, our sample is likely to be representative. In addition, a wide range of demographic and clinical variables, including service use-related factors and specific scales such as HoNOS and 'risk assessment', were analyzed.

However, several limitations should be borne in mind when interpreting our results. First, the sample was formed of secondary mental health services users living in south-east London, an inner-urban area, and results may not generalise to people receiving mental health input from primary care or those in rural areas. Second, HoNOS and risk assessment ratings were available for only a small percentage of the whole sample, and there were clear differences between diagnoses in completion rates. Also, we can speculate that those patients without SSD who had HONOS and risk assessment completed were deemed 'at-high-risk' patients by their clinical teams. In addition, although just the last HONOS and risk assessment were considered for the analyses, the time from that assessment to dying from suicide should be taken into account when drawing associations of causality since risk factors evaluated by those instruments may have changed over the study period. Hence, our findings regarding HONOS and risk assessment ratings differences across diagnoses should be considered cautiously. In keeping with the above, it should be noted that a wide range of variables have been taken over a prolonged period of time, which also varies across the study patients, who ranged from having one single assessment to several years under secondary mental healthcare, thus reflecting the real-world nature of our data. However, the two main variables of interest for this study, namely a SSD diagnosis, which has been demonstrated to have a high diagnostic stability over time [32], and suicide completion can be considered independent of time.

\section{Conclusions}

Our findings show that patients with SSD who end their lives have usually been deemed by their clinicians as being at greater need of risk assessment and accordingly they tend to be more closely monitored, including completion of full risk assessment and HoNOS. However, such evaluated 'known' risk factors for suicide appear to be more relevant in those patients with non-SSD. Moreover, most of the individuals who had SSD included in 
this study had been seen by a mental health professional shortly before dying by suicide, jumping being the most common suicide method.

A successful approach for suicide prevention is likely to require a combination of both population-level strategies such as restricting access to lethal means and measures focused on high-risk groups such as patients with SSD. Specifically, our results suggest that the classic suicide risk assessment and prevention approach in secondary mental healthcare may have little relevance for patients with SSD.

\section{Abbreviations}

WHO: World Health Organization; HONOS: Health of the nation outcome scale; SSD: Schizophrenia spectrum disorder; SLaM: South London \& Maudsley NHS foundation trust; BRC: Biomedical research centre; CRIS: Clinical record interactive search; ONS: Office for National Statistics; ICD-10: International classification of mental and behavioural disorders; IMD: Index of multiple deprivations.

\section{Competing interests}

Authors have no competing interests to disclose concerning the subject of this article. Funding support is detailed in the section of Acknowledgements.

\section{Authors' contributions}

All the authors listed contributed themselves in the process of hypothesis generation, data collection, statistical analyses or manuscript preparation and fulfilled the criteria for authorship. JDLM, ACF, MB and RD carried out the data retrieval and statistical analyses. JDLM wrote the first draft of the manuscript. $\mathrm{CKC}, \mathrm{RDH}, \mathrm{RS}$ and ASD conceived of the study, participated in its design, and implemented the project. All the authors read and approved the final manuscript.

\section{Acknowledgments}

The development of the SLaM BRC Case Register was funded by two Capital Awards from the UK National Institute for Health Research and is further supported through the BRC Nucleus funded jointly by the Guy's and St Thomas' Trustees and South London and Maudsley Special Trustees. JDLM is funded by the British Medical Association via the Margaret Temple Research Award for Schizophrenia.

$\mathrm{RD}$ is funded by a Clinician Scientist Fellowship awarded by the Academy of Medical Sciences in partnership with The Health Foundation.

All authors are part-funded by the National Institute for Health Research (NIHR) Biomedical Research Centre and Dementia Biomedical Research Unit at South London and Maudsley NHS Foundation Trust and King's College London. The funders had no role in hypothesis generation, study design, data collection and analysis, decision to publish or the manuscript writing.

\section{Author details}

${ }^{1}$ Department of Psychosis Studies, King's College London, Institute of Psychiatry, De Crespigny Park, PO Box 68, London SE5 8AF, UK. ²Department of Psychological Medicine, King's College London, Institute of Psychiatry, London, UK

Received: 9 April 2014 Accepted: 18 July 2014 Published: 1 August 2014

\section{References}

1. World Health Organization: Public Health Action for the prevention of suicide. Geneva: WHO; 2013.

2. Patton GC, Coffey C, Sawyer SM, Viner RM, Haller DM, Bose K, Vos T, Ferguson J, Mathers CD: Global patterns of mortality in young people: a systematic analysis of population health data. Lancet 2009, 374:881-892.

3. World Health Organization: Suicide Prevention. Geneva: WHO; 2008.

4. Hawton K, van Heeringen K: Suicide. Lancet 2009, 373:1372-1381.

5. Bebbington PE, Minot S, Cooper C, Dennis M, Meltzer H, Jenkins R, Brugha T: Suicidal ideation, self-harm and attempted suicide: results from the British psychiatric morbidity survey 2000. Eur Psychiatry 2010, 25:427-431.

6. Cavanagh JT, Carson AJ, Sharpe M, Lawrie SM: Psychological autopsy studies of suicide: a systematic review. Psychol Med 2003, 33(3):395-405.
7. Hawton K, Harris L, Hall S, Smikin S, Bale E, Bond A: Deliberate self-harm in Oxford, 1990-2000: a time of change in patient characteristics. Psychol Med 2003, 33(6):987-995.

8. Arsenault-Lapierre G, Kim C, Turecki G: Psychiatric diagnoses in $\mathbf{3 2 7 5}$ suicides: a meta-analysis. BMC Psychiatry 2004, 4:37.

9. Kreitman N: The coal gas story. United Kingdom suicide rates 1960-71. Brit J Prev Soc Med 1976, 30:86-93.

10. Bennewith O, Nowers M, Gunnell D: Effect of barriers on the Clifton suspension bridge, England, on local patterns of suicide: implications for prevention. Br J Psychiatry 2007, 190:266-267.

11. Nielssen O, Glozier N, Babidge N, Reutens S, Andrews D, Gerard A, Malhi GS, Large MM: Suicide attempts by jumping and psychotic illness. Aust N Z J Psychiatry 2010, 44:568-573.

12. Brown S: Excess mortality of schizophrenia: A meta-analysis. $\mathrm{Br} J$ Psychiatry 1997, 171:502-508.

13. Saha S, Chant D, McGrath J: A systematic review of mortality in schizophrenia: Is the differential mortality gap worsening over time? Arch Gen Psychiatry 2007, 64(10):1123-1131.

14. Dutta R, Murray RM, Allardyce J, Jones PB, Boydell JE: Mortality in first-contact psychosis patients in the UK: a cohort study. Psychol Med 2012, 42(8):1649-1661.

15. Palmer BA, Pankratz VS, Bostwick JM: The lifetime risk of suicide in schizophrenia: a reexamination. Arch Gen Psychiatry 2005, 62(3):247-253.

16. Miles CP: Conditions predisposing to suicide. J Nerv Ment Dis 1977, 164(4):231-246.

17. Caldwell CB, Gottesman II: Schizophrenics kill themselves too: a review of risk factors for suicide. Schizophr Bull 1990, 16(4):571-589.

18. Hawton K, Sutton L, Haw C, Sinclair J, Deeks JJ: Schizophrenia and suicide: systematic review of risk factors. Br J Psychiatry 2005, 187:9-20.

19. Bakst S, Rabinowitz J, Bromet EJ: Antecedents and patterns of suicide behavior in first-admission psychosis. Schizophr Bull 2009, 36(4):880-889.

20. Pedersen CG, Jensen SO, Gradus J, Johnsen SP, Mainz J: Systematic suicide risk assessment for patients with schizophrenia: a national populationbased study. Psychiatr Serv 2014, 65(2):226-231.

21. Department of Health and Social Security: The Management of Deliberate Self-Harm. London: HMSO; 1984

22. Wing J, Curtis R, Beevor A: 'Health of the Nation': measuring mental health outcomes. Psychiatric Bull 1994, 18(11):690-691.

23. National Institute for Health and Clinical Excellence (NICE): Clinical guidance 16 self-harm. 2004, [http://www.nice.org.uk/Guidance/CG16].

24. Stewart R, Soremekun M, Pereira G, Broadbent M, Callard F, Denis M, Hotopf M, Thornicroft G, Lovestone S: The South London and Maudsley NHS Foundation Trust Biomedical Research Centre (SLAM BRC) case register: development and descriptive data. BMC Psychiatry 2009, 9:51.

25. Office for National Statistics (ONS): Suicide statistics: deaths registered in England and Wales. [http://www.ons.gov.uk/ons/datasets-and-tables/index. html?pageSize $=50 \&$ sortBy $=$ none\&sortDirection $=$ none $\&$ newquery $=$ suicide $\&$ content-type=Reference+table \&content-type=Dataset $]$ Accessed 23 March 2012.

26. World Health Organization, The ICD-10: Classification of Mental and Behavioural Disorders: Diagnostic Criteria for Research. Geneva: WHO; 1993.

27. Linsley KR, Schapira K, Kelly TP: Open verdict v. suicide - importance to research. Br J Psychiatry 2001, 178:465-468.

28. Office for National Statistics: Indices of deprivation 2007 for super output areas. [http://www.neighbourhood.statistics.gov.uk/dissemination/instance Selection.do?JSAllowed=true\&Function $=\& \% 24$ ph $=60 \_61 \&$ Current Pageld=61\&step=2\&datasetFamilyld=1893\&instanceSelection=122838\&Next. $x=19 \&$ Next. $y=17]$.

29. McGuffin P, Farmer A, Harvey I: A polydiagnostic application of operational criteria in studies of psychotic illness. Development and reliability of the OPCRIT system. Arch Gen Psychiatry 1991, 48(8):764-770.

30. Rucker J, Newman S, Gray J, Gunasinghe C, Broadbent M, Brittain P, Baggaley M, Denis M, Turp J, Stewart R, Lovestone S, Schumann G, Farmer A, McGuffin P: OPCRIT+: an electronic system for psychiatric diagnosis and data collection in clinical and research settings. Br J Psychiatry 2011, 199(2):151-155.

31. Morgan C, Charalambides M, Hutchinson G, Murray RM: Migration, ethnicity and psychosis: toward a sociodevelopmental model. Schizophr Bull 2010, 36(4):655-664.

32. Bromet EJ, Naz B, Fochtmann LJ, Carlson GA, Tanenberg-Karant M: Long-term diagnostic stability and outcome in recent first-episode cohort studies of schizophrenia. Schizophr Bull 2005, 31(3):639-649. 
33. Wu CY, Chang CK, Hayes M, Broadbent M, Hotopf M, Stewart R: Clinical risk assessment rating and all-cause mortality in secondary mental healthcare: the South London and Maudsley NHS Foundation Trust Biomedical Research Centre (SLAM BRC) Case Register. Psychol Med 2012, 42(8):1581-1590

34. Fearon P, Kirkbride JB, Morgan C, Dazzan P, Morgan K, Lloyd T, Hutchinson G Tarrant J, Funq WL, Holloway J, Mallet R, Harrison G, Leff J, Jones PB, Murray RM Incidence of schizophrenia and other psychoses in ethnic minority groups: results from the MRC AESOP Study. Psychol Med 2006, 36(11):1541-1550.

35. Kirkbride JB, Boydell J, Ploubidis GB, Morgan C, Dazzan P, McKenzie K, Murray RM, Jones PB: Testing the association between the incidence of schizophrenia and social capital in an urban area. Psychol Med 2008, 38(8): 1083-1094.

36. Aschan L, Goodwin L, Cross S, Moran P, Hotopf M, Hatch SL: Suicidal behaviour in South East London: Prevalence, risk factors and the role of socio-economic status. J Affect Disorders 2013, 150(2):441-449.

37. Gara MA, Vega WA, Arndt S, Escamilla M, Fleck DE, Lawson WB, Lesser I, Neighbors HW, Wilson DR, Arnold LM, Strakowski SM: Influence of patient race and ethnicity on clinical assessment in patients with affective disorders. Arch Gen Psychiatry 2012, 69(6):593-600.

38. McKenzie K: Suicide studies in ethnic minorities: improving the science to help develop policy. Ethn Health 2012, 17(1-2):7-11.

39. McGirr A, Tousignant M, Routhier D, Pouliot L, Chawky N, Marolese HC, Turecki G: Risk factors for completed suicide in schizophrenia and other chronic psychotic disorders: A case-control study. Schizophr Res 2006, 84:132-143.

40. McGirr A, Turecki G: What is specific to suicide in schizophrenia disorder? Demographic, clinical and behavioural dimensions. Schizophr Res 2008, 98:217-224.

41. Law CK, Yip PSF, Chan WSC, Fu K-W, Wong PWC, Law YW: Evaluating the effectiveness of barrier installation for preventing railway suicides in Hong-Kong. J Affect Disorders 2009, 114(1-3):254-262.

42. Cox GR, Owens C, Robinson J, Nicholas A, Lockley A, Williamson M, Cheung YT, Pirkis J: Interventions to reduce suicides at suicide hotspots: a systematic review. BMC Public Health 2013, 13:214.

43. Tarrier N, Haddock G, Lewis S, Drake R, Gregg L, SoCRATES Trial Group: Suicide behaviour over 18 months in recent onset schizophrenic patients: the effects of CBT. Schizophr Res 2006, 83(1):15-27.

44. Mann JJ, Waternaux C, Haas GL, Malone KM: Toward a clinical model of suicidal behavior in psychiatric patients. Am J Psychiatry 1999, 156(2):181-189.

45. Dutta R, Murray RM, Allardyce J, Jones PB, Boydell JE: Early risk factors for suicide in an epidemiological first episode psychosis cohort. Schizoph Res 2011, 126(1-3):11-19.

46. Beck AT, Brown G, Berchick RJ, Stewart BL, Steer RA: Relationship between hopelessness and ultimate suicide: a replication with psychiatric outpatients. Am J Psychiatry 1990, 147(2):190-195.

47. Drake RE, Cotton PG: Depression, hopelessness and suicide in chronic schizophrenia. Br J Psychiatry 1986, 148:554-559.

48. Hor K, Taylor M: Suicide and schizophrenia: a systematic review of rates and risk factors. J Psychopharmacol 2010, 24(4 Suppl):81-90.

49. Amador XF, David AS: Insight and Psychosis. Awareness of Illness in Schizophrenia and Related Disorders. 2nd edition. Oxford, England: University Press; 2004.

50. Lopez-Morinigo JD, Ramos-Rios R, David AS, Dutta R: Insight in schizophrenia and risk of suicide: a systematic update. Compr Psychiatry 2012, 53(4):313-322.

51. Alonso J, Codony M, Kovess V, Angermeyer MC, Katz SJ, Haro JM, De Girolamo G, De Graaf R, Demyttenaere K, Vilagut G, Almansa J, Lépine JP, Brugha TS: Population level of unmet need for mental healthcare in Europe. Br J Psychiatry 2007, 190:299-306.

52. Thornicroft G, Mansella M: The balanced care model: the case for both hospital- and community-based mental healthcare. Br J Psychiatry 2013, 202(4):246-248.

53. Baca-Garcia E, Perez-Rodrigues MM, Diaz Sastre C, Saiz-Ruiz J, de Leon J: Suicidal behaviour in schizophrenia and depression: a comparison. Schizophr Res 2005, 75:77-81.

doi:10.1186/s12888-014-0213-z

Cite this article as: Lopez-Morinigo et al:: Suicide completion in secondary mental healthcare: a comparison study between schizophrenia spectrum disorders and all other diagnoses. BMC Psychiatry 2014 14:213.

\section{Submit your next manuscript to BioMed Central and take full advantage of:}

- Convenient online submission

- Thorough peer review

- No space constraints or color figure charges

- Immediate publication on acceptance

- Inclusion in PubMed, CAS, Scopus and Google Scholar

- Research which is freely available for redistribution 